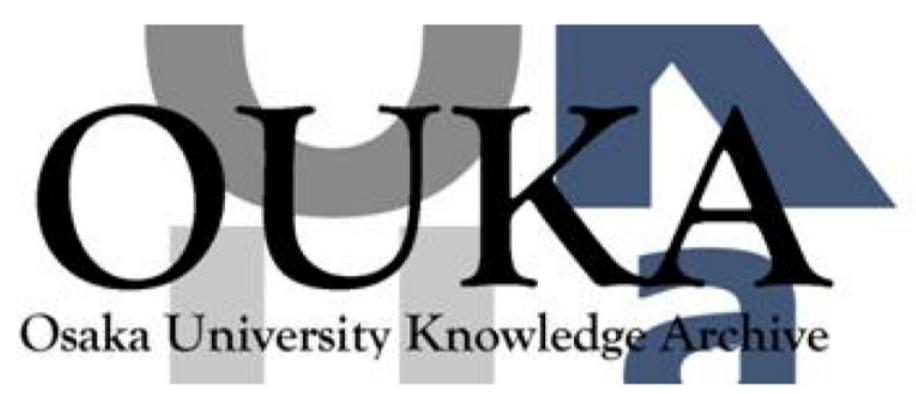

\begin{tabular}{|c|l|}
\hline Title & $\begin{array}{l}\text { Transparent, conductive, and printable } \\
\text { composites consisting of TEMP0-oxidized } \\
\text { nanocellulose and carbon nanotube }\end{array}$ \\
\hline Author(s) & $\begin{array}{l}\text { Koga, Hirotaka; Saito, Tsuguyuki; Kitaoka, } \\
\text { Takuya et al. }\end{array}$ \\
\hline Citation & Biomacromolecules. 14(4) p. 1160-p. 1165 \\
\hline Issue Date & $2013-02-22$ \\
\hline oaire:version & AM \\
\hline URL & https://hdl. handle.net/11094/78438 \\
\hline rights & Copyright $\odot 2013$ American Chemical Society \\
\hline Note & \\
\hline
\end{tabular}

Osaka University Knowledge Archive : OUKA

https://ir. Library. osaka-u. ac. jp/

Osaka University 


\section{Transparent, Conductive and Printable Composites}

\section{Consisting of TEMPO-oxidized Nanocellulose and}

\section{Carbon Nanotube}

Hirotaka Koga $,{ }^{\dagger}, \#, *$ Tsuguyuki Saito, ${ }^{\dagger}$ Takuya Kitaoka, ${ }^{\star}$ Masaya Nogi,$\S$ Katsuaki Suganuma,${ }^{\S}$ and Akira Isogai

${ }^{\dagger}$ Department of Biomaterials Sciences, Graduate School of Agricultural and Life Sciences, The University of Tokyo, Tokyo 113-8657, Japan.

*Department of Agro-environmental Sciences, Graduate School of Bioresource and Bioenvironmental Sciences, Kyushu University, Fukuoka 812-8581, Japan.

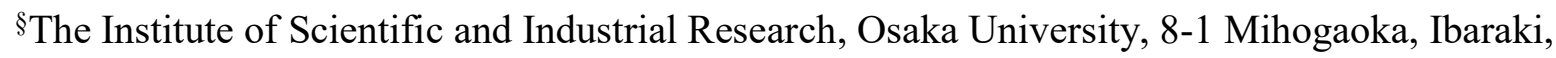
Osaka 567-0047, Japan.

KEYWORDS: carbon nanotube, cellulose single nanofibril, organic-inorganic hybrid, printed electronics, flexible electronics 


\begin{abstract}
Ultra-strong, transparent, conductive and printable nanocomposites were successfully prepared by mixing single-walled carbon nanotubes (CNTs) with 2,2,6,6-tetramethylpiperidine-1-oxyl (TEMPO)-oxidized cellulose nanofibrils (TOCNs) with abundant sodium carboxyl groups on the crystalline nanocellulose surfaces. The surface-anionic cellulose nanofibrils had reinforcing and nano-dispersing effects on the CNTs both in water used as the dispersed medium and in the dried composite film, providing highly conductive and printable nanocomposites with a small amount of CNTs. TOCNs are therefore expected as an effective flexible matrix that can be used as an alternative to conventional polymers for various electrical materials, when nano-composited with CNTs and also graphene. Our findings provide a promising route to realize green and flexible electronics.
\end{abstract}




\section{MAIN TEXT}

\section{INTRODUCTION}

Carbon nanotubes (CNTs) have played an important role in a wide range of research fields because of their remarkable electrical, thermal, and mechanical properties. ${ }^{1}$ The potential applications of CNTs include conductive and reinforcing nanofillers, ${ }^{2}$ batteries, ${ }^{3}$ supercapacitors, ${ }^{4}$ and sensors. ${ }^{5,6}$ CNTs are very difficult to handle because of their small size, so they are frequently used to create composite materials. Recent years have seen considerable progress in the research and development of CNT/polymer composites for various applications; ${ }^{7}$ CNTs have been incorporated in ultra-strong materials applied in bullet-proof vests, in highperformance composites used in the aircraft and automotive industries, ${ }^{7}$ and in flexible electronics applied in thin-film transistors, ${ }^{8}$ flexible electrodes for organic EL displays, ${ }^{9}$ and stretchable conductors. ${ }^{10}$

Of the many organic polymers, cellulose $(\beta-(1,4)$-D-glucopyranose polymer $)$-which originates from higher plants, tunicate, bacteria, and algae - has become attractive from the viewpoint of sustainable development, because cellulose is the most ubiquitous and abundant bioresource. ${ }^{11}$ Recently, some researchers have reported the use of CNTs/cellulose composite materials for flexible electronic applications. ${ }^{12-16}$ For example, flexible energy storage devices based on CNT-integrated cellulose nanocomposite paper were successfully prepared, using an ionic liquid (1-butyl-3-methylimidazolium chloride) as a solvent for the cellulose, and as an electrolyte in the supercapacitor and battery. ${ }^{12}$ In addition, $\mathrm{Hu}$ and co-workers have recently developed CNT/cellulose textiles and papers for wearable electronics and energy storage applications. $^{13-15}$ 
Native cellulose consists of bundles of nanofibrils with widths of 3-50 nm, depending on its origin. Cellulose nanofibrils have outstanding physical properties, including high elastic modulus (ca. $138 \mathrm{GPa})^{17}$ and low thermal expansivity $\left(0.1 \mathrm{ppm} \mathrm{K}^{-1}\right) .{ }^{18}$ These properties are far superior to those of other polymers, but it is difficult to isolate and use individual cellulose nanofibrils, because cellulose has a rigid linear structure with three hydroxyl groups per anhydroglucose unit and therefore cellulose nanofibrils bind tightly to one another through multiple hydrogen bonds. ${ }^{19,20}$ In our previous studies, cellulose single nanofibrils were successfully isolated from native wood celluloses using 2,2,6,6-tetramethylpiperidine-1-oxyl (TEMPO)-mediated oxidation and successive mechanical treatment in water. ${ }^{21,22}$ The TEMPO-oxidized cellulose nanofibrils (TOCNs) with uniform widths of 3-4 nm have physical properties superior to other polymer nanomaterials, including high aspect ratios greater than $250,{ }^{22}$ high elastic modulus (up to 145 $\mathrm{GPa}),{ }^{23}$ and low thermal expansivity $\left(2.7 \mathrm{ppm} \mathrm{K}^{-1}\right) \cdot{ }^{24}$ Moreover, the extremely high densities of carboxylate groups up to $1.7 \mathrm{mmol}$ g-cellulos $\mathrm{e}^{-1}$ on their surfaces (oxidation ratio of the surface glucose units up to 50\%) allow the homogeneous dispersion of completely individual crystalline TOCNs in water because of the electrostatic repulsion between the negatively charged carboxylate ions. ${ }^{22}$ These excellent properties of TOCNs offer great potential for various applications such as high gas-barrier films, ${ }^{24,25}$ strong materials ${ }^{25,26}$ and highly active nanohybrid catalysts. $^{27-29}$ Taking full advantage of TOCNs to boost the physical properties of CNT composites would provide new design opportunities for next-generation devices with low-cost, lightweight, foldable, and portable electronics. Herein, we describe the reinforcing and dispersing effects of TOCNs on CNTs, and the application of the resulting composite materials in green and flexible electronics. The excellent properties of TOCNs allowed the fabrication of 
ultra-strong, ultra-thin, flexible, and printable conductive nanocomposites for transparent conductive films and sensor applications.

\section{EXPERIMENTAL SECTION}

\section{Preparation of an aqueous CNT/TOCN dispersion, and a freestanding CNT/TOCN film.}

An aqueous dispersion of TOCNs (COONa content: $\left.1.33 \mathrm{mmol} \mathrm{g}^{-1}\right)$ was prepared from bleached softwood kraft pulp, using a previously reported method. ${ }^{22}$ An aqueous dispersion of CNTs was prepared as follows: single-walled CNTs treated with nitric acid (4.3 mg, width of 4-5 nm, length of $0.5-1.5 \mu \mathrm{m}, \mathrm{COOH}$ content of ca. $0.22-0.67 \mathrm{mmol} \mathrm{g}{ }^{-1}$, Aldrich, Ltd.) were added to distilled water $(30 \mathrm{~mL})$, and this was followed by sonication for $30 \mathrm{~min}$ using an ultrasonic homogenizer equipped with a $7 \mathrm{~mm}$ probe tip (US-300T, Nihon Seiki), and centrifugation at $9000 \mathrm{rpm}$ for $40 \mathrm{~min}$. Then, the resulting supernatant $(0.003 \mathrm{wt} \%)$ and an aqueous dispersion of TOCNs $(0.1 \mathrm{wt} \%)$ were mixed in a given ratio, to prepare an aqueous CNT/TOCN mixture (30 $\mathrm{mL}$ ). To prepare the freestanding CNT/TOCN film, the mixture was poured into a polystyrene (PS) petri dish, and dried at $40^{\circ} \mathrm{C}$ for 3 days.

Printing of an aqueous CNT/TOCN dispersion on plastic films and paper. Cast coating of CNT/TOCN on plastic films was carried out as follows: polyethylene terephthalate (PET) films (G2, Thickness: $50 \mu \mathrm{m}$ ), provided by Teijin DuPont Films Japan, Ltd., were treated at $10 \mathrm{~mA}$ for 300 s using a plasma etching device (SEDE-PFA, Meiwafosis Co., Ltd.), to improve their wettability. Then, an aqueous dispersion $(2 \mathrm{~mL})$ of CNT/TOCN (CNT: $0.0024 \mathrm{wt} \%$, TOCN: 0.02 $\mathrm{wt} \%)$ was cast on the PET film $(3 \mathrm{~cm} \times 3 \mathrm{~cm})$, and this was followed by drying at room temperature. Ink-jet printing of the dispersion on copy paper was conducted using a Dimatix DMP-2831 inkjet printer (Fujifilm Dimatix, Inc.).

Analyses. The light transmittance of the films was measured using a V-670 spectrophotometer 
(JASCO). AFM observations were performed under ambient conditions, using a NanoScope IIIa atomic force microscope (Veeco Instruments, Inc.) in tapping mode. The tensile strength and Young's modulus of the free-standing films were evaluated at $23{ }^{\circ} \mathrm{C}$ and $50 \% \mathrm{RH}$, using a Shimadzu EZ-TEST instrument equipped with a $500 \mathrm{~N}$ load cell (pulling rate: $1.0 \mathrm{~mm} \mathrm{~min}{ }^{-1}$, span length: $10 \mathrm{~mm}$ ). The electrical properties, including the conductivity, sheet resistance, and resistance were measured using a resistivity meter with a four-point probe (LORESTA-EP, MCP-T360, Mitsubishi Chemical, Ltd.). The relative humidity was controlled using a constant temperature and humidity chamber (LHL-113, ESPEC). For comparison of physical strength and electrical conductivity of the CNT/TOCN film with those of various CNT/polymer films previously reported, the volume fraction of CNTs was calculated assuming that the densities of single-walled CNT and multi-walled CNT were 1.35 and $2.15 \mathrm{~g} \mathrm{~cm}^{-3},{ }^{30}$ respectively, regardless of any functionalization. Then, the densities of TOCN, regenerated cellulose, bacteria cellulose, epoxy resin (diglycidyl ether of bisphenol-A), polypropylene (PP), poly(methyl methacrylate) (PMMA), polyamide-6 and polystyrene (PS) were estimated as $1.60,{ }^{26} 1.60,1.60,1.20,0.9,1.19$, 1.14 and $1.00 \mathrm{~g} \mathrm{~cm}^{-3}$, respectively.

\section{RESULTS AND DISCUSSION}

Physical properties of freestanding CNT/TOCN films. TOCNs were easily extracted from never-dried wood cellulose using our established TEMPO-mediated oxidation system, ${ }^{22}$ and the aqueous dispersion of TOCNs was mixed with single-walled CNTs. Untreated CNTs show poor dispersibility in many solvents, including water, and the chemical modification of CNTs-for example, carboxylation via acid treatment-has therefore been performed frequently. ${ }^{7}$ 
Interestingly, in the presence of TOCNs, untreated CNTs could be successfully dispersed in water to some extent (Figure S1), indicating that completely individualized TOCNs dispersed in water $^{22}$ could act as a dispersing agent for CNTs. It is possible that this interesting phenomenon was due to a $\mathrm{CH}-\pi$ interaction between the axial plane of the cellulose and the graphene $\pi$ conjugated system. ${ }^{31}$ Olivier et al. have recently reported cellulose nanocrystal-assisted dispersion of CNTs. ${ }^{32}$ They have argued that both short-range hydrophobic interactions between the CNTs and specific crystalline faces (hydrophobic (200) planes) of the cellulose nanocrystals and long-range electrostatic repulsion between the sulfated cellulose nanocrystals provide the stabilization of the CNT/cellulose nanocrystal dispersion. TOCNs presumably play similar roles as cellulose nanocrystals, while TOCNs have higher aspect ratios over 250 than whisker-like cellulose nanocrystals $(\sim 50)$, and exhibit excellent nanodispersibility derived from the extremely high densities of carboxylate groups (up to $1.7 \mathrm{mmol}$ g-cellulose ${ }^{-1}$ ) on their surfaces. Such completely individual cellulose nanofibers would lead to superior reinforcement effect, as recently reported by Fujisawa et al. for polystyrene. ${ }^{26}$ To prepare the CNT/TOCN composite films, nitric acid-treated CNTs with carboxyl groups on their surfaces (which showed aqueous dispersibility $^{7}$ due to electrostatic repulsion) were used to increase the CNT contents in the composite films. First, carboxylated CNTs and TOCNs were co-dispersed in water (Figure 1a), and then poured into a polystyrene petri dish. After drying, the CNT/TOCN composite film was obtained. As shown in Figure 1b, the $6.15 \mathrm{wt} \%$ (7.2 vol\%) CNT/TOCN film was freestanding, uniformly black, ultra-thin (thickness ca. $5 \mu \mathrm{m}$ ), flexible like paper, and translucent (transmittance at $\lambda=600 \mathrm{~nm}, \mathrm{~T}_{600 \mathrm{~nm}}$, of ca. 30\%). Figures $1 \mathrm{c}$ and $\mathrm{d}$ show atomic force microscopy (AFM) images of the TOCN films with and without CNTs, respectively. These images indicated that the CNTs were well dispersed in a TOCN matrix. 
Figure 2 compares the physical strength—i.e., the Young's modulus and tensile strength—of the CNT/TOCN films with that of other types of CNT/polymer films collected from the literature. ${ }^{33-38}$ While the Young's modulus and tensile strength of CNTs are as high as $640 \mathrm{GPa}$ and $37 \mathrm{GPa}$, respectively, ${ }^{39}$ those of CNT films (buckypaper) are as low as $1.2 \mathrm{GPa}$ and $10 \mathrm{MPa}$, respectively. ${ }^{40}$ Acid-treated $\mathrm{CNT}$ films have been reported to be stiff (Young's modulus of 8 GPa), but brittle (tensile strength of $30 \mathrm{MPa}) .{ }^{41}$ Hence, CNTs have frequently been used as reinforcing nanofillers for polymers. ${ }^{2,7}$ In the case of conventional polymers such as regenerated cellulose, ${ }^{33}$ polyvinyl alcohol (PVA), ${ }^{34}$ epoxy resin, $,{ }^{35} \mathrm{PP},{ }^{36} \mathrm{PMMA},{ }^{37}$ and polyamide- $6,{ }^{38}$ the physical strength of the CNT/polymer films was increased with increasing CNT content (Figure 2). However, the physical strength of the $\mathrm{CNT} / \mathrm{TOCN}$ film tended to decrease with increasing CNT content. Of all of the samples, the CNT/TOCN film demonstrated the highest Young's modulus (up to ca. $12 \mathrm{GPa}$ ) and tensile strength (up to ca. $250 \mathrm{MPa}$ ). It is noteworthy that the Young's modulus of the CNT/TOCN film was even higher than that of the acid-treated CNT film without TOCNs. These results strongly suggested that TOCNs isolated from wood resources can act as green reinforcement nanomaterials, even for CNTs. In other words, the excellent properties of TOCNs over other cellulose and polymer matrices ${ }^{22}$-which include high aspect ratios, high stiffness, high crystallinity, nanodispersibility - provide great potential for the preparation of ultra-strong and ultra-thin free-standing materials.

Electrical properties of freestanding CNT/TOCN films. Electrical percolation in composites of electrically conductive CNTs and non-conductive polymers has been actively investigated. ${ }^{42}$ According to statistical percolation theory, the dependence of the conductivity $\sigma$ of the composite films on the volume fraction of conductive fillers $\Phi$ can be described by a scaling law of the form 


$$
\sigma=\sigma_{0} \cdot\left(\Phi-\Phi_{\mathrm{c}}\right)^{\mathrm{t}}
$$

where $\sigma_{0}$ and $\Phi_{c}$ are the conductivity of the fillers and the percolation threshold, respectively. ${ }^{42}$ In this theory, the conductivity increases sharply with increases in the volume fraction of conductive fillers above the percolation threshold, when conductive pathways begin to form. The percolation threshold $\Phi_{c}$ is generally determined as follows: experimental results are fitted by plotting $\log \sigma$ versus $\log \left(\Phi-\Phi_{c}\right)$, and incrementally varying $\Phi_{c}$ until the best linear fit is obtained. ${ }^{43}$ The critical exponent $t$ is expected to depend on the sample dimensionality, with calculated values of $t \approx 1.33$ and $t \approx 2.0$ in two and three dimensions, respectively. ${ }^{44,45}$ Figure $3 \mathrm{a}$ compares the experimental and theoretical conductivity values for the CNT/TOCN films. As shown in the inset of Figure $3 \mathrm{a}, \mathrm{a} \Phi_{c}$ value of 0.004 was determined experimentally, indicating that the percolation threshold for the CNTs in the TOCN matrix would be $0.4 \mathrm{vol} \%$. Subsequently, the theoretical line was obtained using equation 2

$$
\sigma=120 \cdot(\Phi-0.004)^{2}
$$

where the $\sigma_{0}$ value of 120 was determined according to the conductivity of the buckypaper prepared using nitric acid-treated $\mathrm{CNTs},{ }^{46}$ and the $t$ value of 2 was determined by taking into consideration the three-dimensional networks of the CNT/TOCN composite. While there was good agreement between the experimental and theoretical values of $\sigma$ below $\Phi=0.048$, the experimentally determined $\sigma$ values were higher than the theoretical values above $\Phi=0.072$. It is speculated that this interesting result may be due to an ionic conduction phenomenon caused by the large amount of ionic COONa groups on the surfaces of the TOCNs $\left(1.33 \mathrm{mmol} \mathrm{g}{ }^{-1}\right)$, which could have provided some improvement in the conductivity of the CNT/TOCN films. In fact, the CNT/TOCN films demonstrated higher conductivity (up to $10 \mathrm{~S} \mathrm{~cm}^{-1}$ ) than other $\mathrm{CNT} /$ polymer films, including those made using regenerated cellulose, ${ }^{33}$ bacterial cellulose, ${ }^{47}$ polyethylene 
$(\mathrm{PE}){ }^{48} \mathrm{PS},{ }^{49}$ and polyamide-6 ${ }^{38}$ (Figure $3 \mathrm{~b}$ ). The sheet resistance of the freestanding CNT/TOCN film was as low as $300 \Omega \Upsilon^{-1}$ (Figure S2), which indicated sufficient conductivity for the film to be used in touch-panel applications. ${ }^{7}$ Thus, ultra-strong, ultra-thin, flexible, and conductive films were successfully prepared with a small amount of CNTs by using woodderived and nano-dispersed TOCNs as an effective matrix.

Printable conductive nanoink consisting of an aqueous CNT/TOCN dispersion. Printed electronics have recently attracted much attention as a next-generation technology to create electrical devices on a roll of flexible substrates, and there is an increasing need for electrically conductive inks for printed electronic applications. ${ }^{50}$ In this study, an aqueous CNT/TOCN dispersion (Figure 1a) was applied as printable nanoink to provide conductive properties for various substrates. As shown in Figure 4a, this dispersion was cast on a PET film; the asprepared film demonstrated uniformly low surface resistance $\left(1.2 \pm 0.1 \mathrm{k} \Omega \Upsilon^{-1}\right)$. The decrease in the $\mathrm{T}_{600 \mathrm{~nm}}$ of the PET film was only $10 \%$ after casting (from ca. $80 \%$ to ca. $70 \%$, Figure $\mathrm{S} 3$ ). For CNTs without TOCNs, the aggregation of CNTs was clearly observed, and this aggregation led to an increase in the surface resistance (Figure 4b). These results suggested that the TOCNs acted as an effective dispersing agent for CNTs even after drying. Figure $4 \mathrm{c}$ shows the use of the CNT/TOCN-cast PET film as a transparent conductive film, which had sufficient electrical conductivity to light a light-emitting diode (LED). In addition, the resistance values for the casted film were responsive to relative humidity, indicating the potential for use as a humidity sensor (Figure 4d and Figure S4). Then, the casted film kept material integrity even at high relative humidity up to $95 \%$. CNTs have been reported to adsorb and desorb molecules including water, leading to changes in their conductivity. ${ }^{1,51}$ This result suggested that the CNT/TOCN dispersion could be used for printable sensors. Furthermore, the composite dispersion was ink-jet 
printable on various substrates, including copy paper, allowing the design of electrical circuits (Figure 4e). Thus, the successful use of TOCNs as a dispersing agent for CNTs provided promising nanoinks for a wide range of printed electronic applications.

\section{CONCLUSION}

In conclusion, ultra-strong and water-dispersible TOCNs - which were easily obtained from renewable wood resources - were effectively used as reinforcing and dispersing agents for CNTs, providing ultra-strong, flexible, and printable conductive nanocomposites. This novel concept could be applied for various electrical materials such as graphene, and breaks new ground in creating green and flexible electronics for a wide range of applications.

\section{Captions for Figures}

Figure 1. Optical images of (a) the aqueous dispersion of carboxylated CNTs/TOCNs after centrifugation at $9000 \mathrm{rpm}$ for $40 \mathrm{~min}$, and (b) the $6.15 \mathrm{wt} \% \mathrm{CNT} / \mathrm{TOCN}$ freestanding film on the color-printed words "cellulose" on copy paper. AFM images of the TOCN films (c) with, and (d) without CNTs.

Figure 2. Physical strength of the freestanding CNT/polymer films versus the volume fraction of CNTs. Measurement conditions: $23{ }^{\circ} \mathrm{C}, 50 \%$ RH. Regenerated cellulose: acid-treated singlewalled CNT (SWNT). ${ }^{33}$ PVA: SWNT with multiple hydroxyl groups. ${ }^{34}$ Epoxy resin: aminoterminated amide derivative of SWNT. ${ }^{35}$ PP: SWNT. ${ }^{36}$ PMMA: SWNT. ${ }^{37}$ Polyamide-6: multiwalled CNT (MWNT). ${ }^{38}$ TOCN: acid-treated SWNT (this study). 
Figure 3. Electrical conductivity of freestanding CNT/polymer films versus volume fraction of CNTs. (a) Correlation between the conductivity $\sigma$ of the CNT/TOCN film and the volume fraction of CNTs $\Phi$; the closed circles and dashed line represent the experimental data and the prediction from the percolation model, respectively. (b) Comparison of the CNT/TOCN film with other $\mathrm{CNT} /$ polymer films reported previously. Measurement conditions: $23{ }^{\circ} \mathrm{C}, 50 \% \mathrm{RH}$. Regenerated cellulose: acid-treated SWNT. ${ }^{33}$ Bacteria cellulose: acid-treated MWNT. ${ }^{47} \mathrm{PE}$ : MWNT. ${ }^{48}$ PS: SWNT. ${ }^{49}$ Polyamide-6: MWNT. ${ }^{38}$ TOCN: acid-treated SWNT (this study).

Figure 4. Optical images and sheet resistance values at $23{ }^{\circ} \mathrm{C}$ and $50 \% \mathrm{RH}$ for (a) the $\mathrm{CNT} / \mathrm{TOCN}$, and (b) the CNT cast on a PET film; these films with a size of $3 \mathrm{~cm} \times 3 \mathrm{~cm}$ were laid on the color-printed words "cellulose" on copy paper. (c) The lighting of an LED using a transparent conductive film based on the CNT/TOCN-cast PET. (d) Correlation between the resistance values of the $\mathrm{CNT} / \mathrm{TOCN}$-cast PET film at $30{ }^{\circ} \mathrm{C}$, and the relative humidity. The relative humidity was changed from low to high values. (e) Ink-jet printed CNT/TOCN line on copy paper. 
Figure 1
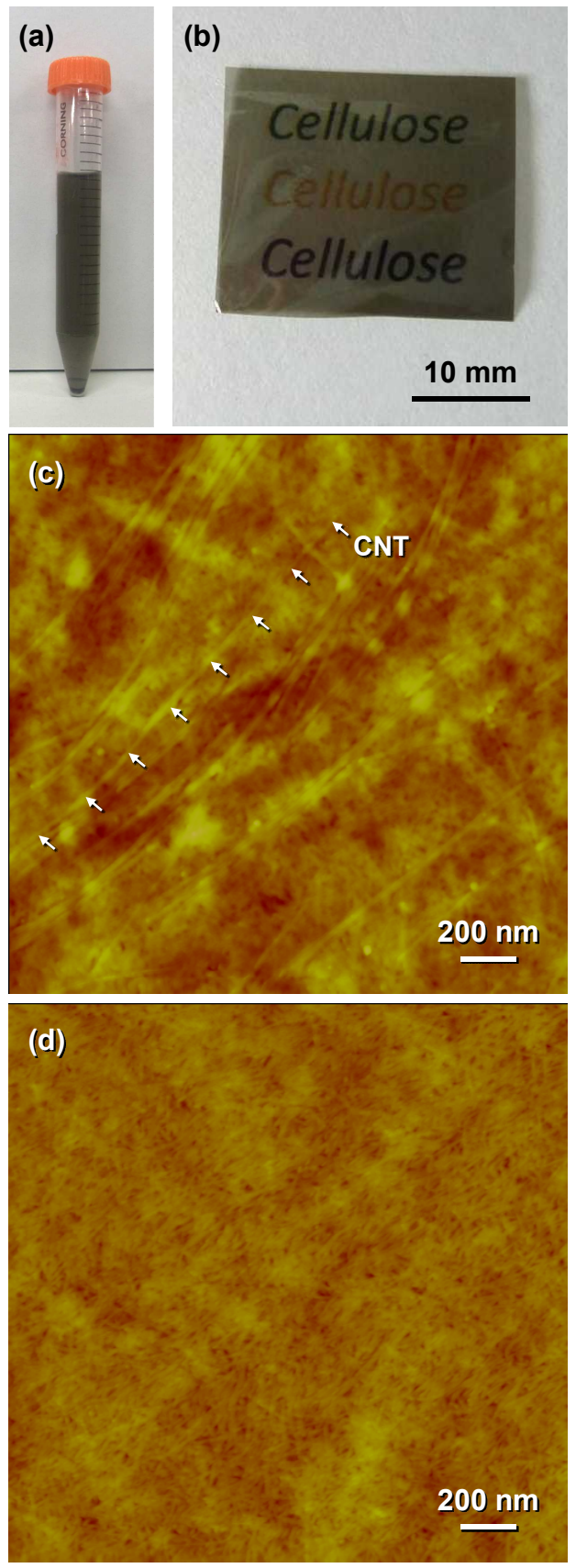
Figure 2

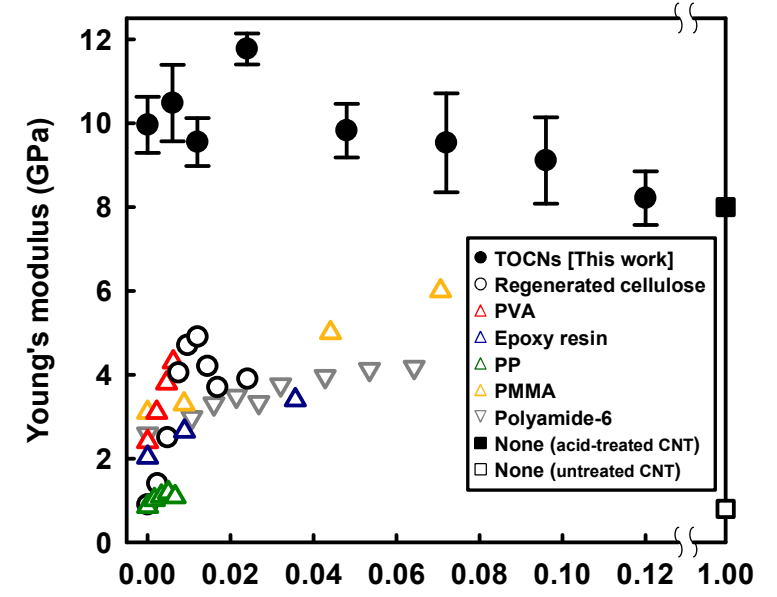

Volume fraction of carbon nanotubes

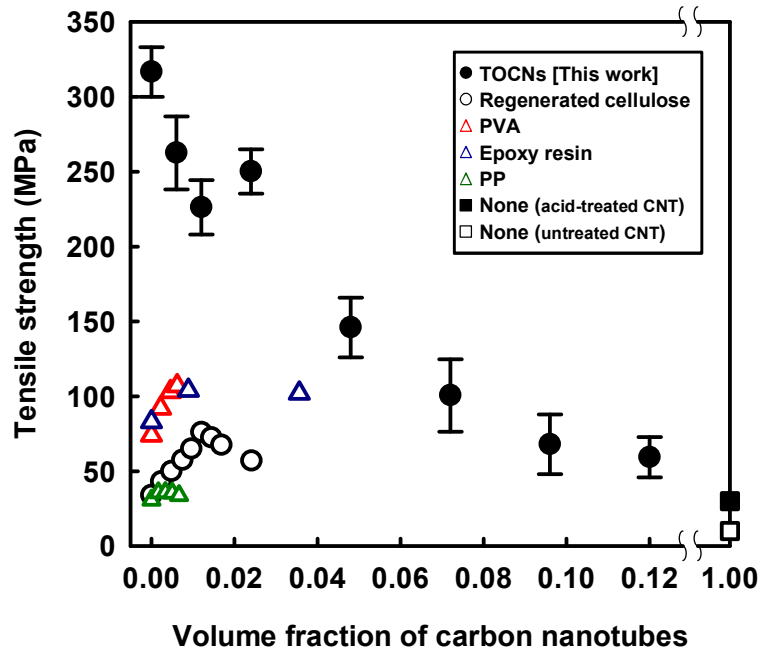

Volume fraction of carbon nanotubes 
Figure 3
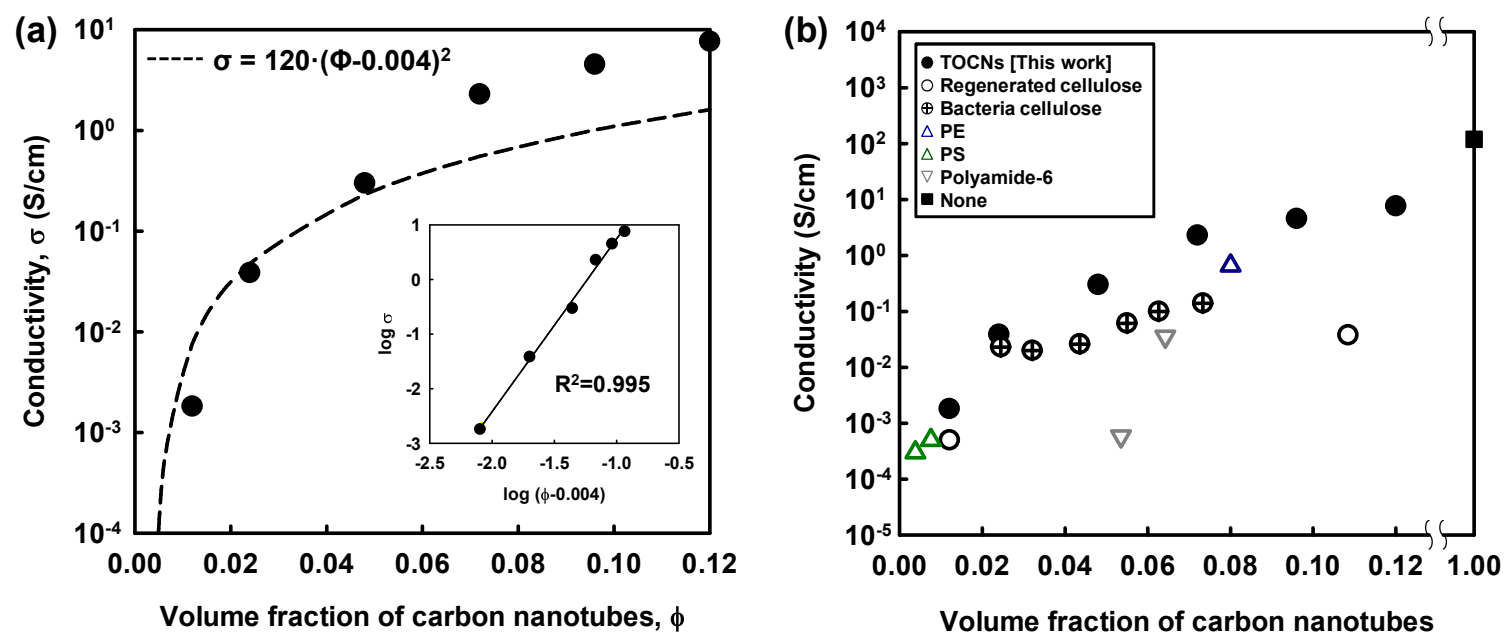
Figure 4

(a)

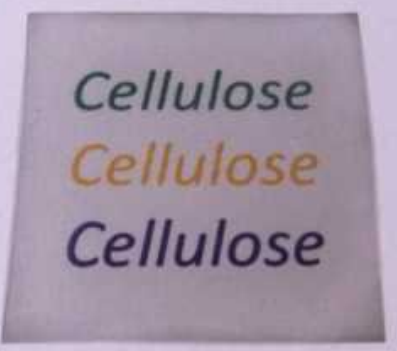

Sheet resistance: $1.2 \pm 0.1 \mathrm{k} \Omega \mathrm{Y}^{-1}$

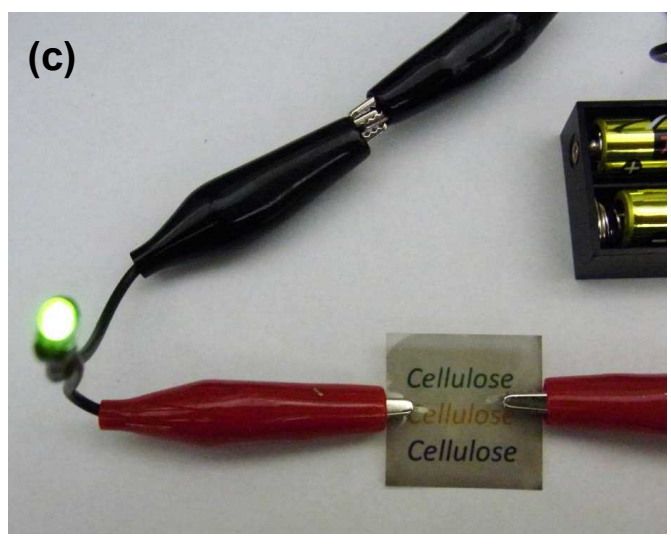

(b)

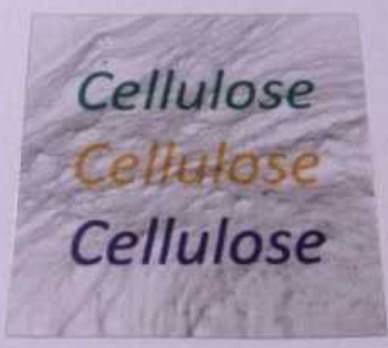

Sheet resistance: $5.8 \pm 2.8 \mathrm{k} \Omega \mathrm{Y}^{-1}$

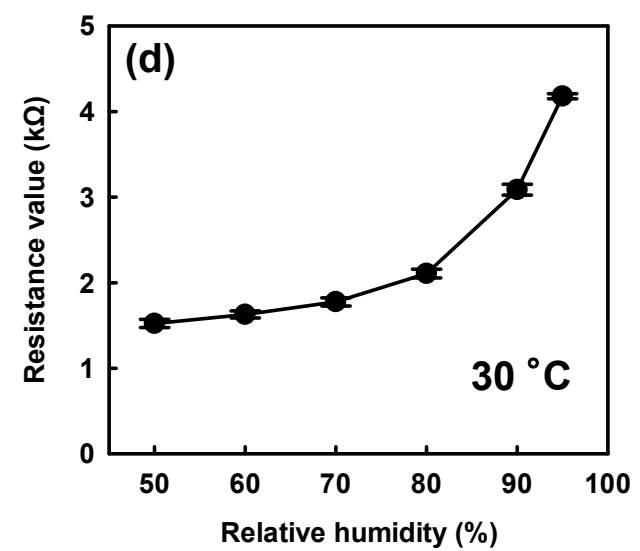

(e)

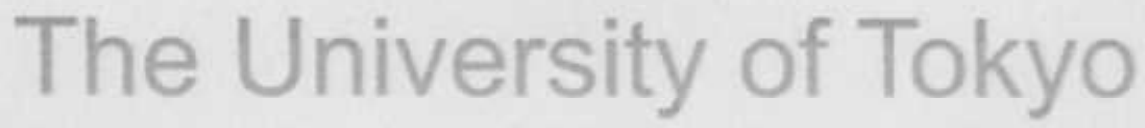

$10 \mathrm{~mm}$ 


\section{ASSOCIATED CONTENT}

Supporting Information Available: Optical images of the aqueous suspensions of untreated CNTs after centrifugation at $9000 \mathrm{rpm}$ for $40 \mathrm{~min}$ in the absence and presence of TOCNs, sheet resistance values for the freestanding CNT/TOCN film versus the volume fraction of CNTs, UVvis light transmittance spectra for an original PET film, and the CNT/TOCN-cast film, resistance values for the $\mathrm{CNT} / \mathrm{TOCN}$-cast film as a function of time, at various relative humidity values. This material is available free of charge via the Internet at http://pubs.acs.org.

\section{AUTHOR INFORMATION}

\section{Corresponding Author}

*Hirotaka Koga

The Institute of Scientific and Industrial Research, Osaka University

8-1 Mihogaoka, Ibaraki, Osaka 567-0047, Japan

Phone: +81-6-6879-8521; Fax: +81-6-6879-8522

E-mail address: hkoga@eco.sanken.osaka-u.ac.jp

\section{Present Addresses}

${ }^{\#}$ The Institute of Scientific and Industrial Research, Osaka University, 8-1 Mihogaoka, Ibaraki, Osaka 567-0047, Japan.

\section{Author Contributions}


The manuscript was written through contributions of all authors. All authors have given approval to the final version of the manuscript.

\section{ACKNOWLEDGMENTS}

H.K. was supported by a Research Fellowship for Young Scientists from the Japan Society for the Promotion of Science, and A.I. by Grants-in-Aid for Scientific Research (S) from the Ministry of Education, Culture, Sports, Science and Technology (Japan). 


\section{REFERENCES}

1. Cao, Q.; Rogers, J. A. Adv. Mater. 2009, 21, 29-53.

2. Coleman, J. N.; Khan, U.; Gun'ko, Y. K. Adv. Mater. 2006, 18, 689-706.

3. Landi, B. J.; Ganter, M. J.; Cress, C. D.; DiLeo, R. A.; Raffaelle, R. P. Energy Environ. Sci. 2009, 2, 638-654.

4. Chen, Z.; Augustyn, V.; Wen, J.; Zhang, Y.; Shen, M.; Dunn, B.; Lu, Y. Adv. Mater. 2010, 23, $791-795$.

5. Kong, J.; Franklin, N. R.; Zhou, C.; Chapline, M. G.; Peng, S.; Cho, K.; Dai, H. Science 2000, $287,622-625$.

6. An, K. H.; Jeong, S. Y.; Hwang, H. R.; Lee, Y. H. Adv. Mater. 2004, 16, 1005-1009.

7. Byrne, M. T.; Gun'ko, Y. K. Adv. Mater. 2010, 22, 1672-1688.

8. Zhang J.; Wang, C.; Zhou, C. ACS Nano 2012, 6, 7412-7419.

9. Cai, L.; Li, J.; Luan, P.; Dong, H.; Zhao, D.; Zhang, Q.; Zhang, X.; Tu, M.; Zeng, Q.; Zhou, W.; Xie, S. Adv. Funct. Mater. 2012, 22, 5238-5244.

10. Azoubel, S.; Shemesh, S.; Magdassi, S. Nanotechnology 2012, 23, 344003.

11. Klemm, D.; Heublein, B.; Fink, H. -P.; Bohn, A. Angew. Chem. Int. Ed. 2005, 44, 3358-3393.

12. Pushparaj, V. L.; Shaijumon, M. M.; Kumar, A.; Murugesan, S.; Ci, L.; Vajtai, R.; Linhardt, R. J.; Nalamasu, O.; Ajayan, P. M. Proc. Natl. Acad. Sci. U. S. A. 2007, 104, 13574-13577. 
13. Hu, L.; Choi, J. W.; Yang, Y.; Jeong, S.; Mantia, F. L.; Cui, L. -F.; Cui, Y. Proc. Natl. Acad. Sci. U. S. A. 2009, 106, 21490-21494.

14. Hu, L.; Pasta, M.; Mantia, F. L.; Cui, L. -F.; Jeong, S.; Deshazer, H. D.; Choi, J. W.; Han, S. M.; Cui, Y. Nano Lett. 2010, 10, 708-714.

15. Hu, L.; Wu, H.; Mantia, F. L.; Yang, Y.; Cui, Y. ACS Nano 2010, 4, 5843-5848.

16. Bao, L.; Li, X. Adv. Mater. 2012, 24, 3246-3252.

17. Nishino, T.; Takano, K.; Nakamae, K. J. Polym. Sci., Part B: Polym. Phys. 1995, 33, 16471651.

18. Nishino, T.; Matsuda, I.; Hirao, K. Macromolecules 2004, 37, 7683-7687.

19. Hult, E. -L.; Larsson, P. T.; Iverson, T. Polymer 2001, 42, 3309-3314.

20. Suchy, M.; Kontturi, E.; Vuorinen, T. Biomacromolecules 2010, 11, 2161-2168.

21. Saito, T.; Nishiyama, Y.; Putaux, J. -L.; Vignon, M.; Isogai, A. Biomacromolecules 2006, 7, $1687-1691$.

22. Isogai, A.; Saito, T.; Fukuzumi, H. Nanoscale 2011, 3, 71-85.

23. Iwamoto, S.; Kai, W.; Isogai, A.; Iwata, T. Biomacromolecules 2009, 10, 2571-2576.

24. Fukuzumi, H.; Saito, T.; Iwata, T.; Kumamoto, Y.; Isogai, A. Biomacromolecules 2009, 10, $162-165$.

25. Wu, C. -N.; Saito, T.; Fujisawa, S.; Fukuzumi, H.; Isogai, A. Biomacromolecules 2012, 13, $1927-1932$. 
26. Fujisawa, S.; Ikeuchi, T.; Takeuchi, M.; Saito, T.; Isogai, A. Biomacromolecules 2012, 13, $2188-2194$.

27. Koga, H.; Tokunaga, E.; Hidaka, M.; Umemura, Y.; Saito, T.; Isogai, A.; Kitaoka, T. Chem. Commun. 2010, 46, 8567-8569.

28. Azetsu, A.; Koga, H.; Isogai, A.; Kitaoka, T. Catalysts 2011, 1, 83-96.

29. Koga, H.; Azetsu, A.; Tokunaga, E.; Saito, T.; Isogai, A.; Kitaoka, T. J. Mater. Chem. 2012, $22,5538-5542$.

30. Coleman, J. N.; Cadek, M.; Ryan, K. P.; Fonseca, A.; Nagy, J. B.; Blau, W. J.; Ferreira, M. S. Polymer 2006, 47, 8556-8561.

31. Yokota, S.; Ueno, T.; Kitaoka, T.; Wariishi, H. Carbohydr. Res. 2007, 342, 2593-2598.

32. Olivier, C.; Moreau, C.; Bertoncini, P.; Bizot, H.; Chauvet, O.; Cathala, B. Langmuir 2012, $28,12463-12471$.

33. Kim, D. -H.; Park, S. -Y.; Kim, J.; Park, M. J. Appl. Polym. Sci. 2010, 117, 3588-3594.

34. Liu, L.; Barber, A. H.; Nuriel, S.; Wagner, H. D. Adv. Funct. Mater. 2005, 15, 975-980.

35. Zhu, J.; Peng, H.; Rodriguez-Macias, F.; Margrave, J. L.; Khabashesku, V. N.; Imam, A. M.; Lozano, K.; Barrera, E. V. Adv. Funct. Mater. 2004, 14, 643-648.

36. López Manchado, M. A.; Valentini, L.; Biagiotti, J.; Kenny, J. M. Carbon 2005, 43, $1499-1505$.

37. Haggenmueller, R.; Gommans, H. H.; Rinzler, A. G.; Fischer, J. E.; Winey, K. I. Chem. Phys. 
Lett. 2000, 330, 219-225.

38. Meincke, O.; Kaempfer, D.; Weickmann, H.; Friedrich, C.; Vathauer, M.; Warth, H. Polymer 2004, 45, 739-748.

39. Baughman, R.; Zakhidov, A. A.; de Heer, W. A. Science 2002, 297, 787-792.

40. Baughman, R.; Cui, C.; Zakhidov, A. A.; Iqbal, Z.; Barisci, J. N.; Spinks, G. M.; Wallace, G. G.; Mazzoldi, A.; De, R. D.; Rinzler, A. G.; Jaschinski, O.; Roth, S.; Kertesz, M. Science 1999, $284,1340-1344$.

41. Sreekumar, T. V.; Liu, T.; Kumar, S.; Ericson, L. M.; Hauge, R. H.; Smalley, R. E. Chem. Mater. 2003, 15, 175-178.

42. Bauhofer, W.; Kovacs, J. Z. Compos. Sci. Technol. 2009, 69, 1486-1498.

43. Kilbride, B. E.; Coleman, J. N.; Fraysse, J.; Fournet, P.; Cadek, M.; Drury, A.; Hutzler, S.; Roth, S.; Blau, W. J. J. Appl. Phys. 2002, 92, 4024-4030.

44. Stauffer, D.; Aharony, A. Introduction to Percolation Theory; Taylor \& Francis: London, 1992

45. Sahimi, M. Applications of Percolation Theory; Taylor \& Francis: London, 1994

46. Zhang, X.; Sreekumar, T. V.; Liu, T.; Kumar, S. J. Phys. Chem. B 2004, 108, 16435-16440.

47. Yoon, S. H.; Jin, H. -J.; Kook, M. -C.; Pyun, Y. R. Biomacromolecules 2006, 7, 1280-1284.

48. O’Connor, I.; De, S.; Coleman, J. N.; Gun'ko, Y. K. Carbon 2009, 47, 1983-1988.

49. Mu, M.; Walker, A. M.; Torkelson, J. M.; Winey, K. I. Polymer 2008, 49, 1332-1337. 
50. Perelaer, J.; Smith, P. J.; Mager, D.; Soltman, D.; Volkman, S. K.; Subramanian, V.; Korvink, J. G.; Schubert, U. S. J. Mater. Chem. 2010, 20, 8446-8453.

51. Cao, C. L.; Hu, C. G.; Fang, L.; Wang, S. X.; Tian, Y. S.; Pan, C. Y. J. Nanomater. 2011, 2011, Article ID 707303. 
Table of contents graphic

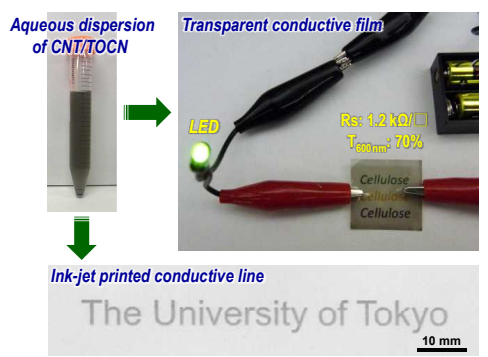


Supporting Information

\title{
Transparent, Conductive and Printable Composites Consisting of TEMPO-oxidized Nanocellulose and Carbon Nanotube
}

\author{
Hirotaka Koga, * Tsuguyuki Saito, Takuya Kitaoka, Masaya Nogi, Katsuaki Suganuma, \\ and Akira Isogai
}

*Corresponding author: H. Koga

The Institute of Scientific and Industrial Research, Osaka University

8-1 Mihogaoka, Ibaraki, Osaka 567-0047, Japan

Phone: +81-6-6879-8521, Fax: +81-6-6879-8522

E-mail address: hkoga@eco.sanken.osaka-u.ac.jp 


\section{Experimental}

\section{Preparation of an aqueous dispersion of untreated CNTs, and TOCNs}

Untreated CNTs (4.3 mg, Aldrich, Ltd.) were mixed with an aqueous dispersion of TOCNs (0.1 $\mathrm{wt} \%, 20 \mathrm{~mL}$ ), and this was followed by sonication for $20 \mathrm{~min}$ using an ultrasonic homogenizer equipped with a $7 \mathrm{~mm}$ probe tip (US-300T, Nihon Seiki), and centrifugation at $9000 \mathrm{rpm}$ for 40 $\min$. 

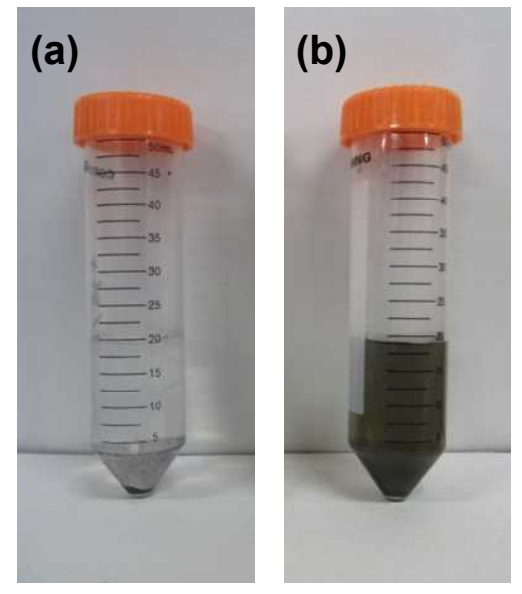

Figure S1. Optical images of the aqueous suspensions of untreated CNTs after centrifugation at $9000 \mathrm{rpm}$ for $40 \mathrm{~min}$ in the (a) absence, and (b) presence of TOCNs. 


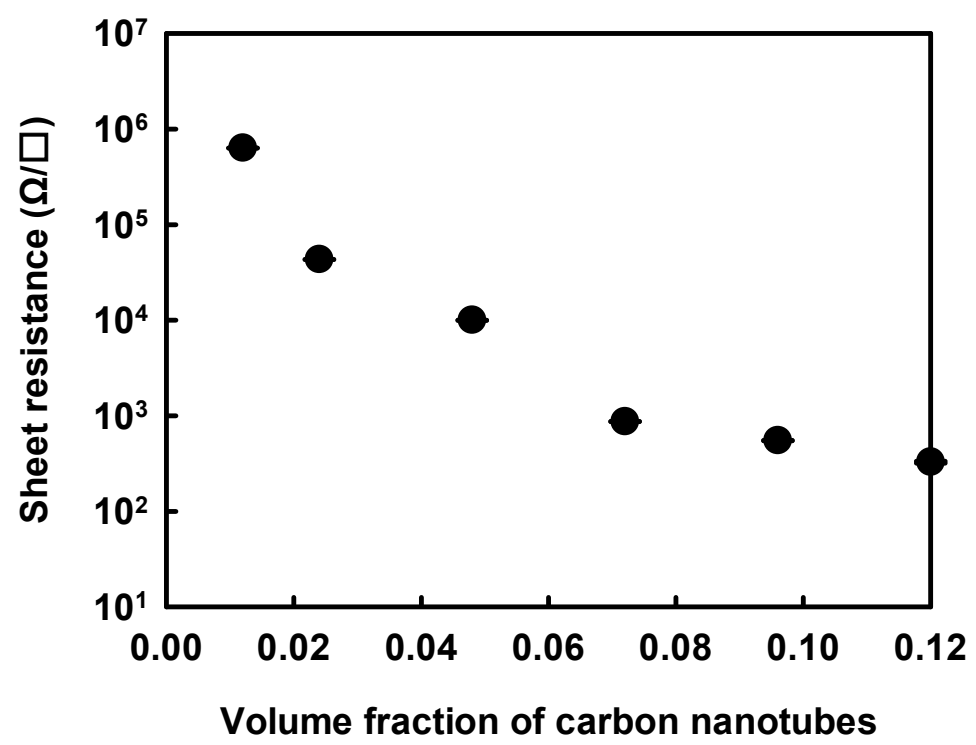

Figure S2. Sheet resistance values for the freestanding CNT/TOCN film versus the volume fraction of CNTs. 


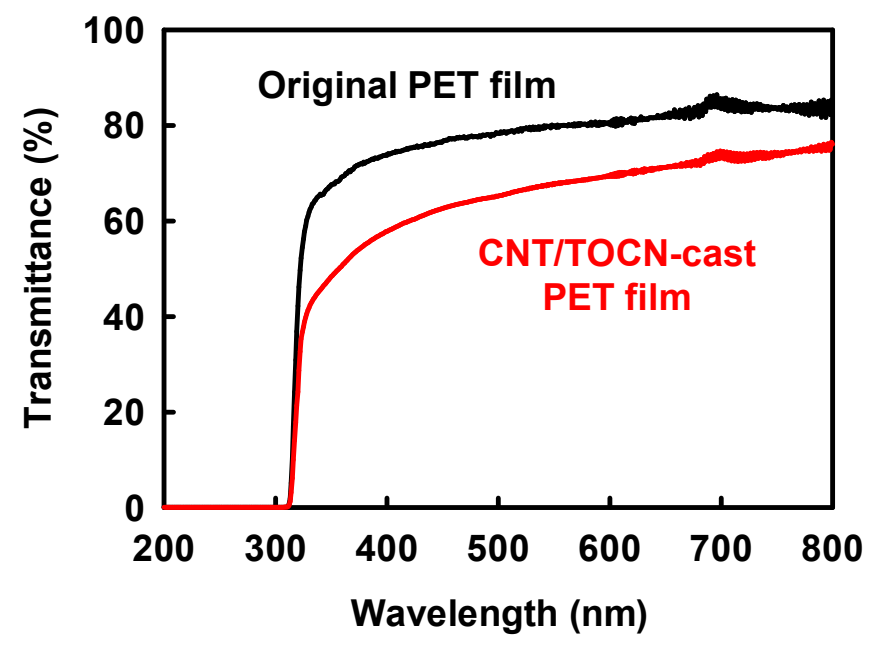

Figure S3. UV-vis light transmittance spectra for an original PET film (black line), and the CNT/TOCN-cast film (red line). 


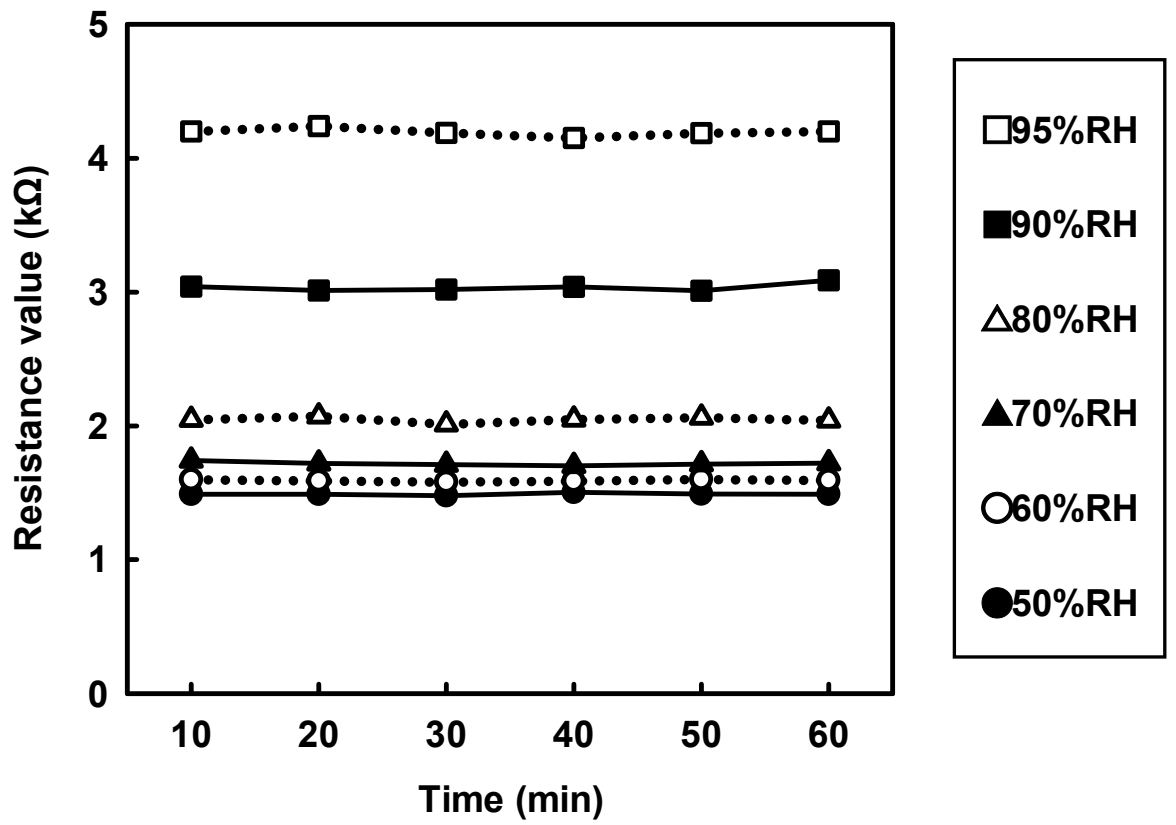

Figure S4. Resistance values for the CNT/TOCN-cast film as a function of time, at various relative humidity values. 